\title{
Fibroepithelioma of Pinkus
}

\author{
Bartos $\mathrm{V}^{1}$, Pokorny $\mathrm{D}^{1}$, Zacharova $\mathrm{O}^{1}$, Kullova $\mathrm{M}^{2}$, Adamicova $\mathrm{K}^{3}$, Pec $\mathrm{M}^{4}$ \\ Department of Pathological Anatomy, Faculty Hospital, Comenius University, Zilina, Slovakia. \\ bartos@jfmed.uniba.sk
}

\begin{abstract}
Basal cell carcinoma $(\mathrm{BCC})$ is recently the most common cancer in humans characterized by several histopathological subtypes. Fibroepithelioma of Pinkus (FEP) is traditionally classified as a very rare variant of BCC, however, it manifests clinical and morphological differences that distinguish it from most other types BCCs. This study was performed to evaluate the incidence of FEP and clinical-pathological characteristics of patients diagnosed with this tumor. Four cases of primary FEP ( 3 females, 1 male, mean age 53.4 y) were analyzed retrospectively. The prevalence of FEP was $0.7 \%$ of all diagnosed BCCs. Topographically, tumors were localized on the right brachium, right gluteal region, left mesogastrium, and right side of the abdomen. Histological examination showed typical anastomosing cords of basaloid cells extending from the overlying epidermis into the loose fibrous stroma in the dermis. Mitotic activity or significant cellular atypia, as well as sign of solar dermatosis were absent. Mean horizontal and vertical diameter of the lesions were 7.7 and $2.8 \mathrm{~mm}$, retrospectively. We did not observe infiltration of deeper skin structures. All lesions were removed completely and classified as pathological stage pT1. Three cases manifested typical picture of a "pure" FEP, one lesion had partially a feature of nodular type BCC, too. Although FEP is conventionally considered as indolent BCC variant with a favorable clinical outcome, recent evidences also favors its classification as a form of trichoblastoma. This is appropriate example how some types of cutaneous tumors can overlap in terms of dignity and clinical-morphological characteristics. This should be taken into account in differential diagnosis and in predicting of biological behaviour of the individual tumors of the skin (Tab. 2, Fig. 3, Ref. 26). Full Text in PDF www.elis.sk.

Key words: fibroepithelioma of Pinkus, basal cell carcinoma, trichoblastoma.
\end{abstract}

Basal cell carcinoma (BCC, basalioma) is recently the most common cancer in human population. It is characterized by several distinct clinical-morphological variants, of which nodular, superficial, and infiltrative are the most frequent $(1,2)$. Fibroepithelioma of Pinkus (FEP) presents a very uncommon indolent variety of this carcinoma $(3,4,5,6)$. It was first described in 1953 by Hermann Pinkus (7) as a premalignant fibroepithelial skin tumor that gave rise to many tiny $\mathrm{BCC}$ within each lesion. The histomorphologic appearance of FEP is usually typical. Tumor is composed of elongated, thin, and branching basaloid epithelial strands arising from the overlying epidermis. These strands are anastomosing and loosely surrounded by a myxoid or fibromucinous stroma of the corium. Occasional eccrine ducts may be present within these strips of tumor cells $(1,5,6,8)$. Although FEP is traditionally considered as a variant of BCC, it manifests several clinical and morphological differences that distinguish it from most other types of BCCs. Therefore, more recent evidence consider it rather to be a "benign analogue" of basalioma and favors its classification as

${ }^{1}$ Department of Pathological Anatomy, Faculty Hospital, Comenius University, Zilina, ${ }^{2}$ Department of Dermatovenerology, Faculty Hospital, Comenius University, Zilina, ${ }^{3}$ Institute of Pathological Anatomy, Jessenius Faculty of Medicine, Comenius University, Martin, and ${ }^{4}$ Institute of Medical Biology, Jessenius Faculty of Medicine, Comenius University, Martin, Slovakia

Address for correspondence: V. Bartos, MD, ul. P. Mudrona 30/16, SK03601 Martin, Slovakia.

Phone: +0908386352 a form of trichoblastoma $(2,9,10)$. This study was performed to evaluate the incidence of FEP and clinical-pathological characteristics of patients with this tumor and to review literature evidence.

\section{Patients and methods}

Four cases of FEP ( 3 females, 1 male) were diagnosed at the Department of Pathology in the Faculty Hospital in Zilina during 3.5-years period (from January 2007 to June 2010). Clinical data of the patients and histomorphological findings were analyzed retrospectively. The age of the individuals ranged between 42-66 years (mean age $53.5 \mathrm{y}$, man $44 \mathrm{y}$, women $56.7 \mathrm{y}$ ). Skin tumors were obtained at the Department of Surgery and Dermatology by total surgical excisions and all were removed completely. All lesions were classified as primary cancer, we observed no case of recurrence. Biopsy material was fixed in buffered formalin, embedded in paraffin blocks, stained with hematoxyllin and eosin and slides were reviewed by pathologists. Clinical data were received from the clinical documentation or by consultations with the clinicians. None of the patients suffered from a Gorlin-Goltz syndrome. One women had excised a superficial BCC on the forehead two years ago, the others have not been diagnosed with another skin malignancy.

\section{Results}

Out of total number of primary BCCs diagnosed during the observed period in our department (577 tumors), FEP represented 


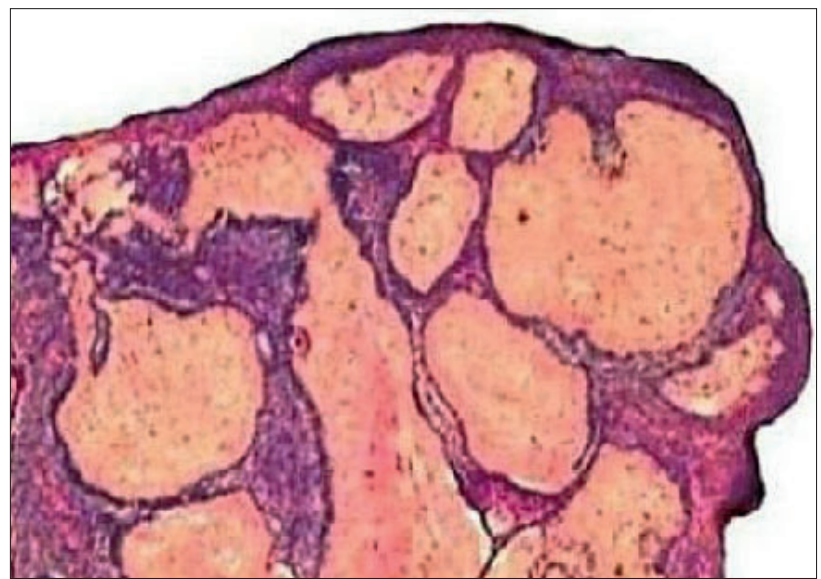

Fig. I. FEP consisted of anastomosing cords of basaloid cells extending from the overlying epidermis into the dermis (H\&E, 100x).

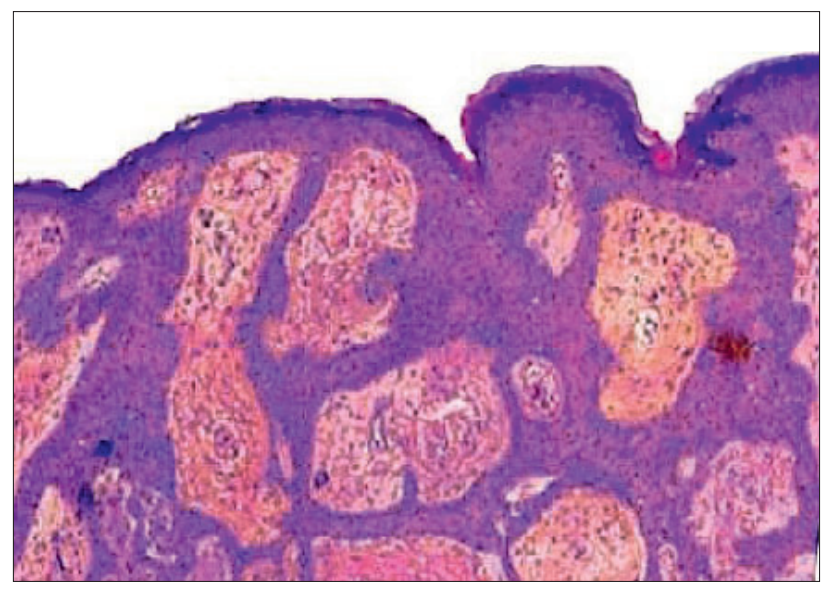

Fig. 2. Tumorous strands are connected each other in fibrotic stroma (H\&E, 200x).

$0.7 \%$ of all cases. According to clinical documentation, there was a several years interval of cancer growth in each patient, but we considered these data as indicative only.

Tumors were topographically localized on the right brachium, right gluteal region, left mesogastrium, and right side of the abdomen, so trunk localisation has been predominated. Grossly, they appeared as well circumscribed nodular, or slightly prominent pink-brown colored skin lesions.

Histological examination of the lesions showed delicate anastomosing cords of basaloid cells extending from the overlying epidermis into the loose fibrous stroma in the dermis (Figs 1, 2 and 3 ). The tumor cells were relatively uniform with a sporadic

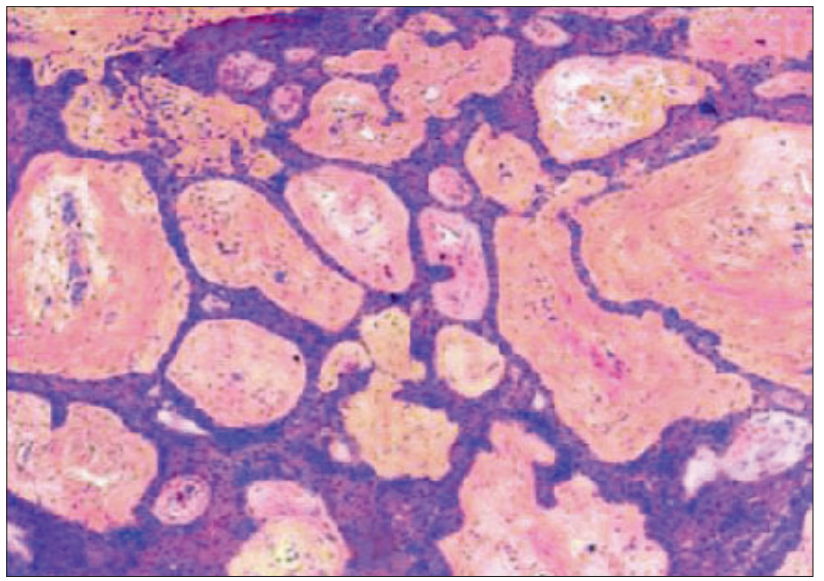

Fig. 3. Detail on anastomosing tumorous strands that ,compartmentalise" surrounded Stroma (H\&E, 400x).

palisade pattern at the periphery of the tumor mass. Melanin pigmentation was focally present. No mitotic activity or significant cellular atypia, as well as signs of infiltrative growth were observed. There was disperse chronic inflammatory infiltration in the surrounding dermis in three cases. No case was histologically accompanied by solar dermatosis. Three cases manifested typical picture of a "pure" FEP without another tumor component, one lesion had also a feature of nodular type BCC at the margin. The largest one was centrally ulcerated on the surface. Horizontal diameter of the lesions ranged between 4-13 $\mathrm{mm}$ (average $7.7 \mathrm{~mm}$ ), vertical diameter $0.3-6.5 \mathrm{~mm}$ (mean $2.8 \mathrm{~mm}$ ). We did not observe infiltration of deeper structures of the skin, thus, all lesions were classified as pathological stage pT1 (Tab. 1).

\section{Discussion}

FEP represents a rare skin neoplasia which prevalence is difficult to estimate objectively. Betti et al. (11) found that $1.2 \%$ of BCCs was constituted by this variant. Adamicova et al $(12,13)$ did not confirm a case of FEP in the set of 100 (12) and 288 (13) retrospective analyzed basaliomas. In our group of patients, FEP comprised $0.7 \%$ of all diagnosed BCCs. These data demonstrate just sporadic occurrence of this lesion in routine clinical practice. On the other hand, in the study of Alakloby et al (14), FEP was the second most common type of BCC representing a total of 5.9 $\%$. These results may indicate regional or ethnic differences in the prevalence of this tumor.

FEP is usually asymptomatic, painless, and appears as either a single or multiple pedunculated or broad-based sessile nodules

Tab. 1. Clinico-pathological parameters of the patients in our group.

\begin{tabular}{|c|c|c|c|c|c|c|c|}
\hline Sex & Age & Locality & HL & VL & $\mathrm{pT}$ & Assoc. component & Ulcer \\
\hline $\bar{F}$ & $42 y$ & right brachium & $4 \mathrm{~mm}$ & $2 \mathrm{~mm}$ & pT1 & nodular type BCC & no \\
\hline $\mathrm{F}$ & $66 \mathrm{y}$ & right gluteal region & $13 \mathrm{~mm}$ & $6.5 \mathrm{~mm}$ & pT1 & ,pure“ & yes \\
\hline M & $44 \mathrm{y}$ & left abdomen & $9 \mathrm{~mm}$ & $2.5 \mathrm{~mm}$ & pT1 & ,pure“ FEP & no \\
\hline $\mathrm{F}$ & $62 \mathrm{y}$ & right abdomen & $5 \mathrm{~mm}$ & $0.3 \mathrm{~mm}$ & $\mathrm{pT} 1$ & „pure“ FEP & no \\
\hline
\end{tabular}

$\mathrm{F}$ - female, $\mathrm{M}$ - male, y - years, HL - horisontal lenght of tumor, VL - vertical lenght of tumor, Ulcer - tumor ulceration, $\mathrm{pT}$ - pathological stage 
Tab. 2. The most important differences between FEP and other "classic" types of BCCs.

\begin{tabular}{|c|c|c|c|c|c|c|}
\hline & Locality & Gender & Solar dermatosis & Merkel cells & Proliferative activity & Biologic behaviour \\
\hline $\begin{array}{l}\text { FEP } \\
\text { otherBCCs }\end{array}$ & $\begin{array}{l}\text { especially trunk and extremities } \\
\text { especially head and neck }\end{array}$ & $\begin{array}{l}\text { mostly in females } \\
\text { mostly in males }\end{array}$ & $\begin{array}{c}\text { rare } \\
\text { frequent }\end{array}$ & $\begin{array}{l}\text { large number } \\
\text { small number }\end{array}$ & $\begin{array}{c}\text { minimal } \\
\text { relatively high }\end{array}$ & $\begin{array}{c}\text { indolent } \\
\text { indolent or aggressive }\end{array}$ \\
\hline
\end{tabular}

with pink, red-brown or flesh-skin color. It mostly occurs in elderly persons, nearly all patients are older than 50 years of age $(4,5,7$, $8,15,16)$. Some authors (5) reported a case occurring in a child, too. Interval between the initial appearance of FEP and histological confirmation of diagnosis is variable, it can range from a few months to several years $(7,15)$. Some studies $(4,9)$ reported time of tumor growth 8-years that give evidence of its clinically favorable character. The most common localization represents the lower trunk or extremities with a predilection for the lumbosacral regions $(4,5,7,8,16)$. However, it has been also described in atypical areas, in which basalioma does not occur, for example penis (17). Roth et al (15) found a relatively high incidence of FEP and BCC with associated FEP component located on the sole. It probably correlates with abundant sweat glands on the plantar surface, in accordance with the proposal that FEP derives its histologic pattern from the spreading of BCC down eccrine ducts and subsequently replacing them with solid strands of tumor $(15,18)$. Even Avci et al (19) reported a BCC with features of FEP located on the nipple in man, area that is rich in mammary gland ducts. Immunohistochemical study of Kurokawa et al (20) supports the theory that FEP may originate from intraepidermal eccrine ducts and proliferate in the dermis.

Since histomorphological picture of FEP is rather typical, diagnosis is relatively easy in most cases. Differential diagnosis includes a reticulated seborrheic keratosis, superficial BCC, eccrine syringofibroadenomas, and mammary intracanalicular fibroadenoma $(1,8)$. However, there have been also described rare histological subtypes, for example a cystic variant (16) or FEP with pleomorphic giant cells $(3,21)$, which can make a histological diagnosis more difficult.

Despite the fact that FEP is currently accepted as indolent variant of BCC with no metastatic potential, it should be stressed that its classification still remains controversial $(5,9,22)$. This tumor has some differences from most BCCs (Tab. 2), whose we confirmed in our cases, too. In contrast to BCC, which is more common in males, FEP has a slight female preponderance. It has an overwhelming predilection for the trunk and extremities, unlike BCC, which occur mostly on the head and neck regions (22). Histologically, only $5 \%$ of FEP are set in a dermis with significant solar dermatosis, feature more commonly found in BCC (22). FEP shows a low level of immunohistochemical staining for tumor suppressor gene product $\mathrm{p} 53$ and proliferative nuclear markers, in contrast to conventional BCCs that usually overexpress these molecules (22). Even from this perspective, the role of the ultraviolet radiation as a potential inductor of FEP carcinogenesis is debatable. FEP also demonstrates retention of Merkel cells (23). However, these cells are found in significantly higher number in both FEP and trichoblastoma compared to BCC (9). Katona et al (10) immunohistochemically identified Merkel cells in $85 \%$ of FEP, $73 \%$ of benign follicular tumors, but only in $27 \%$ of BCC. Since this feature is generally characteristic for benign neoplasms with follicular germinative differentiation but not for BCC, it may indicate relationship of FEP to the trichoblastoma rather than to the BCC. It is possible that regulative influences of the Merkel cells are important for the clinically benign course of FEP or Merkel cells hyperplasia have a causal role in the development of this tumor (23). Given these contrast between FEP and BCC with respect to site of occurrence, relationship to sun damage, histopathologic features, and immunohistochemical studies, it appears that FEP more closely resembles trichoblastoma than BCC (22). Despite of this, definitive immunophenotypic evidence for the classification of FEP remains inconclusive. Androgen receptor (AR) is conversely expressed both in BCC and FEP but just minimally in trichoblastomas. Katona et al (10) detected AR in $77 \%$ of FEP and $73 \%$ of BCC, in 17 $\%$ of trichoepitheliomas, and $0 \%$ of trichoblastomas. Since AR expression is significantly higher in FEP compared to benign follicular skin tumors, but not BCC, this supports its classification as a variant of BCC. In addition, FEP cannot occur only in a "pure" form, as well as in combination with another component of BCC, a finding that encourages its categorization as a form of BCC. Ioannidis et al (2) described FEP in continuity with a nodular BCC. Scalvenzi et al (24) reported two simultaneous histological patterns of BCC in a child - adenoid-cystic, and fibroepithelial. Misago et al (25) presented a very rare case of giant $\mathrm{BCC}$ with features of FEP with an extensive cornification merging with nodular keratotic BCC. Warner et al (26) described FEP that harbored also Paget cells in the epidermis. Thus, pathogenesis of FEP remains still enigmatic, and exact genetic basis has to be elucidated in the future.

\section{Conclusion}

Fibroepithelioma of Pinkus is a very rare indolent skin tumor, which etiology and origin is not fully understood. Although it is conventionally considered as variant of $\mathrm{BCC}$ with favorable clinical outcome, this is appropriate example how some types of cutaneous tumors can overlap in terms of dignity and clinicalmorphological characteristics. This should be taken into account in differential diagnosis and in predicting of biological behaviour of the individual tumors of the skin.

\section{Reference}

1. Crowson AN. Basal cell carcinoma: biology, morphology and clinical implications. Modern Pathol 2006; 19: S127-S147.

2. Ioannidis $\mathbf{O}$, Papaemmanuil $\mathbf{S}$, Kakoutis $\mathbf{E}$ et al. Fibroepithelioma of Pinkus in continuity with nodular basal cell carcinoma: Supporting evidence of the malignant nature of the disease. Pathol Oncol Res 2011; 17 (1): $155-157$. 
3. Repertinger SK, Stevens T, Markin N et al. Fibroepithelioma of Pinkus with pleomorphic epithelial giant cells. Dermatol Online J 2008; 14 (12): 13.

4. Lee D, Chun JS, Seol JE et al. Fibroepithelioma of Pinkus resembling seborrheic keratosis on the thigh. Korean J Dermatol 2010; 48 (1): 69-71.

5. Pan Z, Huynh N, Sarma DP. Fibroepithelioma of pinkus in a 9-yearboy: a case report. Cases J 2008; 1: 21.

6. Kossard S, Epstein EH Jr, Cerio R et al. Basal cell carcinoma. In: LeBoit P (Eds). World Health Organization Classification of Tumours, Pathology and Genetics of Skin tumours, IARCPress, Lyon, 2006; pp. 13-19 ISBN 92-832-2414-0.

7. Pinkus H. Premalignant fibroepithelial tumors of skin. Arch Dermatol Syphilol 1953; 67: 598-615.

8. Cohen PR, Tschen JA. Fibroepithelioma of Pinkus presenting as a sessile thigh nodule. Skinmed 2003; 2 (6): 385-387.

9. Su MW, Fromer E, Fung MA. Fibroepithelioma of pinkus. Dermatol Online J 2008; 12 (5): 2.

10. Katona TM, Ravis SM, Perkins SM et al. Expression of androgen receptor by fibroepithelioma of Pinkus: evidence supporting classification as a basal cell carcinoma variant? Am J Dermatopathol 2007; 29 (1): 7-12.

11. Betti R, Inselvini E, Carducci M, Crosti C. Age and site prevalence of histologic subtypes of basal cell carcinomas. Int J Dermatol 1995; 34 (3): 174-176.

12. Adamicova K, Fetisovova $Z$, beseda $A$ et al. Invasive basalioma regarding the view of pathologists and clinicians. Bratisl Lek Listy 1995; 96: $148-151$.

13. Adamicova K, Fetisovova Z, Mellova Y, Argalacsova S. Invasive type of basal cell carcinoma. Lek Listy, priloha ZdN 2004; 17: 4-5.

14. Alakloby MO, Bukhari IA, Shawarby MA. Histopathological pattern of non-melanoma skin cancer at King Fahd Hospital of the University in the Eastern Region of Saudi Arabia during the years 1983 to 2002. Cancer Therapy 2008; 6: 303-306.
15. Roth MJ, Stern JB, Haupt HM et al. Basal cell carcinoma of the sole. J Cutan Pathol 1995; 22: 349-353.

16. Jones CC, Ansari SJ, Tschen JA. Cystic fibroepithelioma of Pinkus. J Cutan Pathol 1991; 18: 220-222.

17. Heymann WR, Soifer I, Burk PG. Penile premalignant fibroepithelioma of Pinkus. Cutis 1983; 10: 519-521.

18. Stern JB, Haupt HM, Smith RR. Fibroepithelioma of Pinkus: eccrine duct spread of basal cell carcinoma. Am J Dermatopathol 1994; 16: 585-587.

19. Avci O, Pabuççuoğlu U, Koçdor MA et al. Basal cell carcinoma of the nipple - an unusual location in a male patient. J Dtsch Dermatol Ges 2008; 6 (2): 130-132.

20. Kurokawa I, Yokoyama T, Nishimura K et al. Pinkus tumor may originate from intraepidermal eccrine ducts and proliferate in the dermis. Oncol Rep 2007; 17 (1): 49-54.

21. Val-Bernal JF, Gómez-Ortega JM, Fernández-Llaca H, GomézRomán JJ. Fibroepithelioma of pinkus with tumor giant cells. Am J Dermatopathol 2002; 24 (4): 336-339.

22. Bowen AR, LeBoit PE. Fibroepithelioma of pinkus is a fenestrated trichoblastoma. Am J Dermatopathol 2005; 27 (2): 149-154.

23. Hartzchuh W. Schulz T. Merkel cell hyperplasia in chronic radiationdamaged skin: its possible relationship to fibroepithelioma of Pinkus. J Cutan Pathol 1997; 24 (8): 477-483.

24. Scalvenzi M, Francia MG, Falleti J, Balato A. Basal cell carcinoma with fibroepithelioma-like histology in a healthy child: report and review of the literature. Pediatr Dermatol 2008; 25 (3): 359-363.

25. Misago N, Suzuki Y, Miura Y, Narisawa Y. Giant polypoid basal cell carcinoma with features of fibroepithelioma of Pinkus and extensive cornification. Eur J Dermatol 2004; 14 (4): 272-275.

26. Warner TFCS, Burges JH, Mohs FE. Extramaminary Paget's disease in fibroepithelioma of Pinkus. J Cutan Pathol 1982; 9 (5): 340-344.

Received August 21, 2010. Accepted June 26, 2012. 